\title{
Analisis Kelayakan Isi LKS "Pintar Pendidikan Agama Islam Berkarakter" Kelas V SD
}

\author{
Lisa Yulia Sari ${ }^{1}$, Muhammad Aufa Muis ${ }^{2}$ \\ ${ }^{1}$ Fakultas Ilmu Sosial, Universitas Negeri Padang, Padang \\ ${ }^{2}$ Fakultas Tarbiyah, Sekolah Tinggi Agama Islam Negeri Bengkalis, Bengkalis \\ *Corresponding author, e-mail: lisayuliasari27@gmail.com
}

\begin{abstract}
This study aims to identify and describe the results of the feasibility analysis of the contents of the Islamic Religious Education Smart LKS content in terms of the suitability of the material description with $K I / K D$, the accuracy of the material, and the content of supporting learning materials. The type of research used is library research. Literature research is research based on literature searches related to the problems to be discussed. The method used is descriptive analysis method. The primary data sources in this study were obtained from the Smart LKS for Islamic Religious Education with Character, while the secondary data were obtained from books, journals, articles, laws and regulations, and so on. All data will be collected, analyzed, interpreted as well as by interpreting the object under study. The results showed that the suitability of the description of the material with KI-KD obtained a percentage of $65 \%$, while in terms of the accuracy of the material it obtained a percentage of $72 \%$, and in terms of supporting learning materials it obtained a percentage of $73.2 \%$. When viewed as a whole, the percentage of sub-components is $70 \%$, which shows that the Smart LKS for Islamic Religious Education is worthy of being used as a companion book for learning in elementary schools.
\end{abstract}

Keywords: Feasibility of Content, Smart LKS, Islamic Religious Education

This is an open access article distributed under the Creative Commons 4.0 Attribution License, which permits

unrestricted use, distribution, and reproduction in any medium, provided the original work is properly cited. C2018 by author.

\section{Pendahuluan}

Menurut Innana (dalam Kholida \& Satria, 2021) pendidikan adalah usaha yang dilakukan oleh individu secara terencana untuk membimbing individu lain agar dapat berkembang menjadi manusia mandiri, bertanggung jawab, berilmu dan berakhlak mulia. Untuk mewujudkan individu tersebut, diperlukan pembelajaran Pendidikan Agama Islam dalam rangka membentuk karakter siswa yang berakhlakul kharimah. Menurut Thoha dan Mu'thi (dalam Samrin, 2015) menyatakan bahwa pendidikan agama Islam merupakan usaha sadar untuk menyiapkan peserta didik dalam memahami, meyakini, menghayati dan mengamalkan nilai-nilai agama islam melalui kegiatan bimbingan dan pengajaran atau latihan dengan memperhatikan tuntunan untuk menghormati agama lain. Selanjutnya dapat defenisikan bahwa Pendidikan Agama Islam adalah proses yang dilakukan untuk membentuk manusia atau individu yang beriman dan bertakwa kepada Allah SWT dengan mengamalkan nilai-nilai Islam sesuai dengan ajaran Al-Qur'an dan As-sunnah yang nantinya dapat menjadi pribadi yang berakhlakul kharimah (Samrin, 2015).

Dilihat dari hasil belajar PAI siswa, masih ditemukan hasil yang cenderung menurun. Faktor yang ikut mempengaruhi hasil belajar siswa ini diantaranya adalah buku ajar yang digunakan guru dalam proses pembelajaran. Buku PAI yang digunakan guru ternyata masih belum membuat siswa menjadi aktif dalam pembelajaran. Kebanyakan siswa ketika mengerjakan tugas, lebih terfokus terhadap jawaban yang ada dibuku, padahal siswa hendaknya bisa lebih aktif dengan mencari referensi dari sumber-sumber lain. Kesesuaian bahan ajar dengan standar isi yang ditetapkan oleh pemerintah menjadi sebuah keharusan, selain itu berbagai factor lain seperti media belajar, sarana dan prasaana, serta iklim pembelajaran yang kondusif, juga memengaruhi hasil belajar siswa (Ramah \& Rohman, 2018). 
Saat ini, kelemahan dalam dunia pendidikan lebih diasosiasikan kepada kualitas guru menyampaikan materi pembelajaran utama. Padahal, guru bukanlah satu-satunya sumber belajar bagi peserta didik, yang lebih diharapkan adalah pembelajaran berpusat pada peserta didik itu sendiri. Penentu keberhasilan suatu pembelajaran bukan hanya dari guru semata. Ada hal lain yang sangat mempengaruhi peserta didik dalam proses pembelajaran, diantaranya adalah pengadaan buku dan media belajar sebagai acuan pembelajaran. (Masduqi, 2014).

Salah satu faktor yang mendukung keberhasilan siswa dan guru dalam proses pembelajaran adalah penggunaan buku pendamping pembelajaran atau LKS (Lembar Kerja Siswa). Menurut Suyitno, LKS merupakan salah satu alternatif pembelajaran yang tepat bagi peserta didik, karena LKS dapat membantu peserta didik untuk menambah informasi tentang konsep yang dipelajari melalui kegiatan belajar secara sistematis. LKS adalah media pembelajaran berupa lembaran-lembaran tugas kegiatan siswa yang sesuai dengan SK-KD dan berisi informasi serta petunjuk dalam menyelesaikan tugas, baik secara mandiri ataupun secara berkelompok (Aryani, 2011). Menurut Widyantini, Lembar Kerja Siswa atau sering disingkat LKS yang dibuat oleh guru untuk membantu pelaksanaan pembelajaran di kelas merupakan bagian dari suau bahan ajar. Bahan ajar yaitu segala bentuk bahan yang digunakan untuk membantu guru dalam melaksanakan kegiatan belajar mengajar di kelas (Widyantini, 2013). Dari penjelasan tersebut dapat dipahami bahwa LKS merupakan suatu bahan ajar dalam proses pembelajaran.

Salah satu LKS yang baru digunakan sebagai buku pendamping dalam pembelajaran PAI disekolah adalah buku LKS Pintar Pendidikan Agama Islam Berkarakter. Buku LKS ini adalah karya dari Kelompok Kerja Guru (KKG) Kota Padang. LKS Pintar PAI Berkarakter ini sangat praktis digunakan sebagai buku acuan pendamping pelajaran disekolah. Namun, masih ditemukan permasalahan dalam LKS, diantaranya adalah penggunaan kalimat yang kurang sesuai dengan perkembangan peserta didik, kesalahan dalam penulisan, materi yang belum lengkap/akurat, dan lain sebagainya. Untuk itulah perlu dilakukan analisis terhadap kelayakan isi materi LKS Pintar Pendidikan Agama Islam, sesuai dengan instrument penilaian Badan Standar Nasional Pendidikan (BSNP).

Pada penelitian terdahulu, sudah ditemukan penelitian mengenai Analisi Buku Ajar PAI dan Budi Pekerti oleh Nurochim dan Ngaisah. Dalam penelitian tersebut membahas analisis buku ajar PAI dari segi konsep sikap sosial. Mereka menganalisis dan menyimpulkan bahwa buku ajar PAI dan Budi Pekerti di dalamnya memuat konsep sikap sosial yang ditekankan pada sabar, lemah lembut, kasih sayang, keteladanan, bekerjasama dengan orang lain, menghormati guru, empati, persatuan dan damai, serta sikap pemaaf (Nurochim \& Ngaisah, 2021). Selanjutnya, pada penelitian Rofiqotul Aini dan Nurul Huda juga membahas tentang Analisis Kualitas Buku Ajar PAI di Era Revolusi 4.0. dalam penelitian tersebut, membahas bagaimana kelayakan isi Buku PAI dari segi kelayakan komponen penyajian, kelayakan komponen bahasa, kelayakan komponen kegrafikan.

Dari penelitian tersebut, terlihat bahwa persentase penilaian buku ajar PAI memperoleh nilai 93,68 \% yang artinya buku PAI sangat layak (Aini \& Huda, 2020). Selain itu, ditemukan juga penelitian serupa mengenai Analisis Buku Siswa Tingkat 1 di Sekolah Dasar. Yang menjadi fokus dalam penelitian ini adalah nilai-nilai karakter yang terkandung dalam buku pelajaran PAI dalam Kurikulum 2013. Nilai karakter yang terkandung dalam buku tersebut adalah nilai karakter dalam hubungan dengan Tuhan, nilai karakter dalam hubungan dengan diri sendiri, serta nilai karakter dalam hubungan dengan sesame manusia. Dari penelitian ini kesesuaian pendidikan karakter yang terdapat dalam buku PAI SD secara keseluruhan sudan sesuai, namun perlu disempurnakan lagi dengan pengembangan karakter pada proses pembelajaran (Nasucha, 2019). Adapun yang menjadi ciri Khas dan pembeda dalam penelitian ini adalah buku yang penulis analisis adalah Bahan Ajar (LKS) Pintar Pendidikan Agama Islam karya Kelompok Kerja Guru dengan berdasarkan penilaian Badan Stadar Nasional Pendidikan.

\section{Metode}

Jenis penelitian yang digunakan dalam penelitian ini adalah penelitian kepustakaan (library research). Dalam penelitian ini, menggunakan teknik membaca teks (buku, artikel, dan 
dokumen) menjadi bagian yang fundamental dalam penelitian (Zed, 2014: 4-5). Penelitian kepustakaan (library research) yaitu penelitian yang didasarkan atas penelusuran literaturliteratur yang terkait dengan masalah yang akan dibahas (Sugiyono, 2012: 164). Kemudian, sifat penelitian ini adalah deskriptifanalitis yaitu dengan cara mengumpulkan data, menafsirkan, serta mengadakan analisis dan interpretasi.

Ada dua jenis sumber data dalam penelitian ini, yaitu : (1) data primer (data utama) yakni LKS Pintar Pendidikan Agama Islam Berkarakter Kelas V SD, (2) data sekunder (data pendukung), yakni sumber yang mendukung data data penelitian, diantaranya jurnal, buku teks, majalah, peraturan perundang-undangan dan lain sebagainya. Instrumentasi dalam penelitian ini yaitu menggunakan observasi non-partisipan, dimana peneliti tidak meneliti situasi individu, melainkan mengembangkan hasil analisis. Kemudian, pada penelitian ini juga menggunakan instrument penilaian kelayakan isi buku yang bersumber dari BSNP (Badan Standar Nasional Pendidikan).

Menurut Ghony dan Almansur menyebutkan bahwa analisis data merupakan suatu pencarian pola-pola data prilaku yang muncul, objek-objek yang terkait dengan fokus penelitian (Ghony \& Almansur, 2012). Adapun analisis data yang digunakan pada penelitian ini adalah analisis konten (analysis content), artinya peneliti melakukan analisis terhadap materi atau isi yang ada dalam bahan ajar (data primer). Analisis data tersebut dilakukan secara sistematis dan logis dimulai dari membaca dan menelaah seluruh data yang tersedia, terutama data primer. Setelah seluruh data dipelajari, dicermati, dan ditelaah kemudian peneliti melakukan langkah penilaian berdasarkan instrument penilaian bahan ajar.

Menurut Ghony dan Almansur, (dalam Husnawati, 2018) keabsahan data bertujuan untuk dapat membuktikan dan mempertanggung jawabkan hasil serta kredibilitas penelitian yang dilakukan. Hal ini juga dapat menyanggah pertanyaan yang dapat meragukan penelitian ini. Maka dari itu teknik keabsahan data pada penelitian ini yaitu dengan keajegan/ ketekunan pengamatan berarti mencari secara konsisten interpretasi dengan berbagai cara dalam kaitan dengan proses analisis yang konstan atau interaktif. Maka dari itu, dalam penelitian ini peneliti melakukan telaah dan pengamatan secara teliti, rinci dan mendalam.

\section{Hasil dan Pembahasan}

\section{A. Gambaran Umum LKS Pintar Pendidikan Agama Islam Berkarakter Kelas V SD (Semester 1)}

Secara umum LKS Pintar Pendidikan Agama Islam Berkarakter ini pada setiap bab terbagi menjadi beberapa bagian. Pertama, pada setiap bab nya terdapat halaman yang memuat judul, Peta Konsep, Kompetensi Dasar, Indikator Pembelajaran, dan Tujuan Pembelajaran. Tiap $\mathrm{bab}$, berisi penjelasan dan rangkuman mengenai materi pembelajaran yang sesuai dengan $\mathrm{KI} / \mathrm{KD}$ PAI kelas V SD. Kedua, terdapat kolom diskusi kelompok yang bertujuan agar peserta didik dapat berpikir lebih luas, bertukar pikiran dan bekerjasama dengan teman sejawat. Ketiga, terdapat kolom khulasah (ringkasan materi) yang memudahkan peserta didik mengulang kembali apa saja poin-poin penting yang dibahas dalam materi pembelajaran pada setiap babnya . Keempat, terdapat kolom kisah hikmah yang membuat peserta didik termotivasi untuk terus berbuat baik dan berakhlakul karimah. Kelima, setiap bab pada LKS ini terdapat soal-soal latihan yang bertujuan untuk mengukur sejauh mana pemahaman peserta didik mengenai materi yang telah diajarkan.

1. Kelayakan Isi Kesesuaian Uraian Materi dengan KI/KD (Permen 37 Tahun 2018 tentang KI-KD Tingkat SD, SMP, dan SMA)

Tabel 1

Kategori Penilaian :

Instrumen Penilaian Bahan Ajar Pendidikan Agama Islam

\begin{tabular}{|l|l|l|l|l|l|l|l|l|l|}
\hline \multicolumn{2}{|l|}{ Kurang Sekali } & \multicolumn{4}{l|}{ Kurang } & \multicolumn{2}{l|}{ Baik } & \multicolumn{2}{l|}{ Baik Sekali } \\
\hline $\mathbf{1}$ & $\mathbf{2}$ & $\mathbf{3}$ & $\mathbf{4}$ & $\mathbf{5}$ & $\mathbf{6}$ & $\mathbf{7}$ & $\mathbf{8}$ & $\mathbf{9}$ & $\mathbf{1 0}$ \\
\hline
\end{tabular}

\begin{tabular}{|l|l|l|l|l|}
\hline Pelajaran & Subkomponen & Butir & Nilai & Alasan Penilaian \\
\hline
\end{tabular}




\begin{tabular}{|c|c|c|c|c|}
\hline \multirow[t]{2}{*}{1} & \multirow[t]{2}{*}{$\begin{array}{l}\text { Kesesuaian } \\
\text { Uraian Materi } \\
\text { dengan } \\
\text { KI/KD }\end{array}$} & $\begin{array}{l}\text { Kelengkapan } \\
\text { Materi }\end{array}$ & 5 & $\begin{array}{l}\text { Materi pada Bab } 1 \text { tentang } \\
\text { Mari Membaca Surat At- } \\
\text { Tiin belum lengkap, tidak } \\
\text { sesuai dengan KI/KD }\end{array}$ \\
\hline & & $\begin{array}{l}\text { Kedalaman } \\
\text { Materi }\end{array}$ & 5 & $\begin{array}{l}\text { Materi pada Bab } 1 \text { tentang } \\
\text { Mari Membaca Surat At- } \\
\text { Tiin sudah cukup } \\
\text { mendalami, namun kurang } \\
\text { sesuai dengan KI/KD }\end{array}$ \\
\hline \multirow[t]{2}{*}{2} & \multirow[t]{2}{*}{$\begin{array}{l}\text { Kesesuaian } \\
\text { Uraian Materi } \\
\text { dengan } \\
\text { KI/KD }\end{array}$} & $\begin{array}{l}\text { Kelengkapan } \\
\text { Materi }\end{array}$ & 7 & $\begin{array}{l}\text { Materi pada Bab } 2 \text { tentang } \\
\text { Mengenal Nama Allah dan } \\
\text { Kitab-kitabnya sudah } \\
\text { lengkap, sesuai dengan } \\
\text { KI/KD }\end{array}$ \\
\hline & & $\begin{array}{l}\text { Kedalaman } \\
\text { Materi }\end{array}$ & 6 & $\begin{array}{l}\text { Materi pada Bab } 2 \text { tentang } \\
\text { Mengenal Nama Allah dan } \\
\text { Kitab-kitabnya sudah } \\
\text { cukup mendalami, namun } \\
\text { masih terdapat ketikan } \\
\text { yang salah, sehingga } \\
\text { membingungkan peserta } \\
\text { didik. }\end{array}$ \\
\hline \multirow[t]{2}{*}{3} & \multirow[t]{2}{*}{$\begin{array}{l}\text { Kesesuaian } \\
\text { Uraian Materi } \\
\text { dengan } \\
\text { KI/KD }\end{array}$} & $\begin{array}{l}\text { Kelengkapan } \\
\text { Materi }\end{array}$ & 8 & $\begin{array}{l}\text { Materi pada Bab } 3 \text { tentang } \\
\text { Cita-citaku Menjadi Anak } \\
\text { Sholeh sudah lengkap, } \\
\text { sesuai dengan KI/KD }\end{array}$ \\
\hline & & $\begin{array}{l}\text { Kedalaman } \\
\text { Materi }\end{array}$ & 6 & $\begin{array}{l}\text { Materi pada Bab } 3 \text { tentang } \\
\text { Cita-citaku Menjadi Anak } \\
\text { Sholeh sudah mendalami, } \\
\text { namun masih kurang } \\
\text { dalam pemaknaan istilah } \\
\text { yang digunakan }\end{array}$ \\
\hline \multirow[t]{2}{*}{4} & \multirow[t]{2}{*}{$\begin{array}{l}\text { Kesesuaian } \\
\text { Uraian Materi } \\
\text { dengan } \\
\text { KI/KD }\end{array}$} & $\begin{array}{l}\text { Kelengkapan } \\
\text { Materi }\end{array}$ & 9 & $\begin{array}{l}\text { Materi pada Bab } 4 \text { tentang } \\
\text { Bulan Ramadhan yang } \\
\text { Indah sudah lengkap dan } \\
\text { sesuai dengan KI/KD }\end{array}$ \\
\hline & & $\begin{array}{l}\text { Kedalaman } \\
\text { Materi }\end{array}$ & 9 & $\begin{array}{l}\text { Materi pada Bab } 4 \text { tentang } \\
\text { Bulan Ramadhan yang } \\
\text { Indah sudah mendalami }\end{array}$ \\
\hline \multirow[t]{2}{*}{5} & \multirow[t]{2}{*}{$\begin{array}{l}\text { Kesesuaian } \\
\text { Uraian Materi } \\
\text { dengan } \\
\text { KI/KD }\end{array}$} & $\begin{array}{l}\text { Kelengkapan } \\
\text { Materi }\end{array}$ & 5 & $\begin{array}{l}\text { Materi pada Bab } 5 \text { tentang } \\
\text { Rasul Allah Idolaku belum } \\
\text { lengkap, tidak sesuai } \\
\text { dengan KI/KD }\end{array}$ \\
\hline & & $\begin{array}{l}\text { Kedalaman } \\
\text { Materi }\end{array}$ & 5 & $\begin{array}{l}\text { Materi pada Bab } 5 \text { tentang } \\
\text { Rasul Allah Idolaku sudah } \\
\text { cukup mendalami, namun } \\
\text { kurang sesuai dengan } \\
\text { KI/KD }\end{array}$ \\
\hline $\begin{array}{l}\text { Rangkuman } \\
\text { Kumulatif }\end{array}$ & \multicolumn{4}{|c|}{$\begin{array}{l}\text { Berdasarkan tabel diatas kesesuaian materi berdasarkan KI/KD dari } \\
\text { segi kelengkapan dan kedalaman materi pada keseluruhan bab, terdapat } \\
3 \text { bab yang sesuai dengan KI/KD yaitu pada bab } 2,3 \text {, dan } 4 \text {. Sedangkan } \\
\text { materi pada bab } 1 \text { dan bab } 5 \text { masih kurang lengkap. }\end{array}$} \\
\hline Jumlah & \multicolumn{4}{|l|}{65} \\
\hline $\begin{array}{ll}\text { Jumlah } & \text { skor } \\
\text { maksimal } & \\
\end{array}$ & \multicolumn{4}{|l|}{100} \\
\hline
\end{tabular}




\begin{tabular}{|l|l|}
\hline Presentase & $\mathrm{P}=\frac{f}{N} \times 100 \%$ \\
Kelayakan & $\mathrm{P}=65 \%$ \\
\hline
\end{tabular}

2. Kelayakan Isi Keakuratan Materi sesuai dengan Permen 37 Tahun 2018

Tabel 2

Instrumen Penilaian Bahan Ajar Pendidikan Agama Islam

Kategori Penilaian :

\begin{tabular}{|l|l|l|l|l|l|l|l|l|l|}
\hline \multicolumn{2}{|l|}{ Kurang Sekali } & \multicolumn{4}{l|}{ Kurang } & \multicolumn{2}{l|}{ Baik } \\
\hline $\mathbf{1}$ & $\mathbf{2}$ & $\mathbf{3}$ & $\mathbf{4}$ & $\mathbf{5}$ & $\mathbf{6}$ & $\mathbf{7}$ & $\mathbf{8}$ & $\mathbf{9}$ & $\mathbf{1 0}$ \\
\hline
\end{tabular}

\begin{tabular}{|c|c|c|c|c|}
\hline Pelajaran & Subkomponen & Butir & Nilai & Alasan penilaian \\
\hline \multirow[t]{4}{*}{1} & \multirow[t]{4}{*}{$\begin{array}{l}\text { Keakuratan } \\
\text { Materi }\end{array}$} & $\begin{array}{l}\text { Pemilihan } \\
\text { wacana, teks, } \\
\text { gambar, dan } \\
\text { ilustrasi sesuai } \\
\text { dengan } \\
\text { kompetensi } \\
\text { yang harus } \\
\text { dicapai dan } \\
\text { bermanfaat bagi } \\
\text { pemenuhan } \\
\text { rasa ingin tahu } \\
\text { peserta didik }\end{array}$ & 7 & $\begin{array}{l}\text { Pemilihan wacana, teks, } \\
\text { dan gambar ilustrasi pada } \\
\text { materi pada Bab } 1 \\
\text { tentang Mari Membaca } \\
\text { surat At-Tin sudah sesuai } \\
\text { dengan Kompetensi } \\
\text { dasar yang harus dikuasai } \\
\text { peserta didik } \\
\text { Pada Bab } 1 \text { ini terdapat } \\
\text { gambar ilustrasi yang } \\
\text { sesuai dengan indikator } \\
\text { pembelajaran serta } \\
\text { penjelasan yang } \\
\text { memberikan pemahaman } \\
\text { rasa ingin tahu peserta } \\
\text { didik. }\end{array}$ \\
\hline & & $\begin{array}{l}\text { Konsep dan } \\
\text { teori } \\
\text { dengan } \\
\text { sistematika } \\
\text { keilmuan }\end{array}$ & 8 & $\begin{array}{l}\text { Berdasarkan konsep dan } \\
\text { teori pada bab } 1 \text { materi } \\
\text { tentang Mari Membaca } \\
\text { surat At-Tin sudah sesuai } \\
\text { dengan Kompetensi } \\
\text { Dasar dan penjabaran } \\
\text { materinya juga sudah } \\
\text { sesuai dengan tingkat } \\
\text { pemahaman siswa. }\end{array}$ \\
\hline & & $\begin{array}{l}\text { Pemilihan } \\
\text { contoh sesuai } \\
\text { dengan } \\
\text { kompetensi } \\
\text { yang harus } \\
\text { dicapai }\end{array}$ & 7 & $\begin{array}{l}\text { Pemilihan contoh pada } \\
\text { bab } 1 \text { materi tentang Mari } \\
\text { Membaca surat At-Tiin } \\
\text { sudah sesuai } \\
\text { KI/KD yengan } \\
\text { dicapai oleh peserta } \\
\text { didik. }\end{array}$ \\
\hline & & $\begin{array}{l}\text { Pelatihan, } \\
\text { penugasan, dan } \\
\text { penilaian sesuai } \\
\text { tuntutan } \\
\text { penilaian } \\
\text { autentik }\end{array}$ & 7 & $\begin{array}{l}\text { Pada lembar kerja siswa } \\
\text { seperti penugasan dan } \\
\text { soal-soal latihan bab } 1 \\
\text { materi tentang Mari } \\
\text { Membaca surat At-Tiin } \\
\text { sudah sesuai berdasarkan } \\
\text { penilaian autentik. }\end{array}$ \\
\hline 2 & $\begin{array}{l}\text { Keakuratan } \\
\text { Materi }\end{array}$ & $\begin{array}{l}\text { Pemilihan } \\
\text { wacana, teks, } \\
\text { gambar, dan }\end{array}$ & 6 & $\begin{array}{l}\text { Pemilihan wacana, teks, } \\
\text { dan gambar ilustrasi pada } \\
\text { materi Bab } 2 \text { tentang }\end{array}$ \\
\hline
\end{tabular}




\begin{tabular}{|c|c|c|c|c|}
\hline & & $\begin{array}{l}\text { ilustrasi sesuai } \\
\text { dengan } \\
\text { kompetensi } \\
\text { yang harus } \\
\text { dicapai dan } \\
\text { bermanfaat bagi } \\
\text { pemenuhan } \\
\text { rasa ingin tahu } \\
\text { peserta didik }\end{array}$ & & $\begin{array}{l}\text { Mengenal Nama Allah } \\
\text { dan Kitab-kitab-Nya } \\
\text { sudah sesuai dengan } \\
\text { Kompetensi Dasar yang } \\
\text { harus dikuasai peserta } \\
\text { didik, namun pada } \\
\text { pemilihan gambar masih } \\
\text { terdapat kekeliruan } \\
\text { karena gambar ilustrasi } \\
\text { mengenai kitab Allah } \\
\text { kurang jelas, wacana dan } \\
\text { teks dari penjelasan } \\
\text { materi pada bab ini masih } \\
\text { terdapat kesalahan dalam } \\
\text { penulisan kalimat } \\
\text { sehingga nantinya dapat } \\
\text { membingungkan peserta } \\
\text { didik. }\end{array}$ \\
\hline & & $\begin{array}{lr}\text { Konsep } & \text { dan } \\
\text { teori } & \text { sesuai } \\
\text { dengan } & \\
\text { sistematika } & \\
\text { keilmuan } & \end{array}$ & 7 & $\begin{array}{l}\text { Konsep dan teori pada } \\
\text { bab } 2 \text { tentang Mengenal } \\
\text { Nama Allah dan Kitab- } \\
\text { kitab-Nya sudah sesuai } \\
\text { dengan sistematika } \\
\text { keilmuan berdasarkan } \\
\text { Kompetensi Dasar. }\end{array}$ \\
\hline & & $\begin{array}{l}\text { Pemilihan } \\
\text { contoh sesuai } \\
\text { dengan } \\
\text { kompetensi } \\
\text { yang harus } \\
\text { dicapai }\end{array}$ & 8 & $\begin{array}{l}\text { Pemilihan contoh pada } \\
\text { bab } 2 \text { materi tentang } \\
\text { Mengenal Nama Allah } \\
\text { dan Kitab-kitab-Nya } \\
\text { sudah sesuai dan sudah } \\
\text { mengandung nilai-nilai } \\
\text { moral dalam kehidupan } \\
\text { sehari-hari. }\end{array}$ \\
\hline & & $\begin{array}{l}\text { Pelatihan, } \\
\text { penugasan, dan } \\
\text { penilaian sesuai } \\
\text { tuntutan } \\
\text { penilaian } \\
\text { autentik }\end{array}$ & 8 & $\begin{array}{l}\text { Penugasan dan soal-soal } \\
\text { latihan pada bab } 2 \text { materi } \\
\text { tentang Mengenal Nama } \\
\text { Allah dan Kitab-kitab- } \\
\text { Nya sudah sesuai } \\
\text { berdasarkan penilaian } \\
\text { autentik. }\end{array}$ \\
\hline \multirow[t]{2}{*}{3} & \multirow[t]{2}{*}{$\begin{array}{l}\text { Keakuratan } \\
\text { Materi }\end{array}$} & $\begin{array}{l}\text { Pemilihan } \\
\text { wacana, teks, } \\
\text { gambar, dan } \\
\text { ilustrasi sesuai } \\
\text { dengan } \\
\text { kompetensi } \\
\text { yang harus } \\
\text { dicapai dan } \\
\text { bermanfaat bagi } \\
\text { pemenuhan } \\
\text { rasa ingin tahu } \\
\text { peserta didik }\end{array}$ & 7 & $\begin{array}{l}\text { Pada wacana dan teks } \\
\text { materi bab } 3 \text { tentang Cita- } \\
\text { Citaku menjadi Anak } \\
\text { Sholeh sudah sesuai } \\
\text { dengan KD namun masih } \\
\text { terdapat kalimat-kalimat } \\
\text { yang penggunaannya } \\
\text { kurang tepat. Gambar } \\
\text { ilustrasi yang digunakan } \\
\text { pada bab ini dapat } \\
\text { memberikan pemahaman } \\
\text { terhapat rasa ingin tahu } \\
\text { peserta didik. }\end{array}$ \\
\hline & & \begin{tabular}{|lr} 
Konsep & dan \\
teori & sesuai \\
dengan & \\
\end{tabular} & 7 & $\begin{array}{l}\text { Konsep dan teori pada } \\
\text { bab } 3 \text { materi tentang Cita- } \\
\text { Citaku menjadi Anak }\end{array}$ \\
\hline
\end{tabular}




\begin{tabular}{|c|c|c|c|c|}
\hline & & $\begin{array}{l}\text { sistematika } \\
\text { keilmuan }\end{array}$ & & $\begin{array}{l}\text { Sholeh sudah sesuai } \\
\text { dengan Kompetensi } \\
\text { Dasar dan sistematika } \\
\text { keilmuan, namun masih } \\
\text { terdapat istilah yang } \\
\text { cukup sulit dan tidak } \\
\text { terdapat penjelasan dari } \\
\text { istilah tersebut. }\end{array}$ \\
\hline & & $\begin{array}{l}\text { Pemilihan } \\
\text { contoh sesuai } \\
\text { dengan } \\
\text { kompetensi } \\
\text { yang harus } \\
\text { dicapai }\end{array}$ & 8 & $\begin{array}{lr}\text { Contoh yang } & \text { digunakan } \\
\text { dalam bab } 3 \text { ini sudah } \\
\text { sesuai } & \text { dengan } \\
\text { Kompetensi } & \text { dasar. } \\
\text { Contoh yang diberikan } \\
\text { sesuai } & \text { dengan } \\
\text { pengalaman } & \text { dalam } \\
\text { kehidupan sehari-hari. }\end{array}$ \\
\hline & & $\begin{array}{l}\text { Pelatihan, } \\
\text { penugasan, dan } \\
\text { penilaian sesuai } \\
\text { tuntutan } \\
\text { penilaian } \\
\text { autentik }\end{array}$ & 8 & $\begin{array}{l}\text { Dalam pelatihan, } \\
\text { penugasan dan penilaian } \\
\text { pada bab } 3 \text { tentang Cita- } \\
\text { Citaku menjadi Anak } \\
\text { Sholeh sudah sesuai } \\
\text { dengan tuntutan } \\
\text { penilaian autentik. }\end{array}$ \\
\hline 4 & $\begin{array}{l}\text { Keakuratan } \\
\text { Materi }\end{array}$ & $\begin{array}{l}\text { Pemilihan } \\
\text { wacana, teks, } \\
\text { gambar, dan } \\
\text { ilustrasi sesuai } \\
\text { dengan } \\
\text { kompetensi } \\
\text { yang harus } \\
\text { dicapai dan } \\
\text { bermanfaat bagi } \\
\text { pemenuhan } \\
\text { rasa ingin tahu } \\
\text { peserta didik }\end{array}$ & 7 & $\begin{array}{l}\text { Wacana dan teks pada } \\
\text { materi bab } 4 \text { tentang } \\
\text { Bulan Ramadhan yang } \\
\text { Indah sudah sesuai } \\
\text { dengan } \\
\text { Dasar, nompetensi } \\
\text { banyak nam masih } \\
\text { kelasahan } \\
\text { penulisan terdapat } \\
\text { sehingga } \\
\text { membingungkan peserta } \\
\text { didik. selain itu gambar } \\
\text { ilustrasi } \\
\text { dimunculkan pada bab } \\
\text { ini. }\end{array}$ \\
\hline & & $\begin{array}{l}\text { Konsep dan } \\
\text { teori sesuai } \\
\text { dengan } \\
\text { sistematika } \\
\text { keilmuan }\end{array}$ & 8 & $\begin{array}{l}\text { Materi pada bab } 4 \\
\text { tentang Bulan Ramadhan } \\
\text { yang Indah sudah sesuai } \\
\text { dengan konsep dan teori } \\
\text { sesuai Kompetensi Dasar } \\
\text { yang harus dicapai. }\end{array}$ \\
\hline & & $\begin{array}{l}\text { Pemilihan } \\
\text { contoh sesuai } \\
\text { dengan } \\
\text { kompetensi } \\
\text { yang harus } \\
\text { dicapai }\end{array}$ & 6 & $\begin{array}{l}\text { Pemilihan contoh yang } \\
\text { digunakan dalam materi } \\
\text { bab } 4 \text { tentang Bulan } \\
\text { Ramadhan yang Indah } \\
\text { sudah sesuai dengan } \\
\text { Kompetensi Dasar yang } \\
\text { harus dicapai peserta } \\
\text { didik. }\end{array}$ \\
\hline & & $\begin{array}{l}\text { Pelatihan, } \\
\text { penugasan, dan }\end{array}$ & 6 & $\begin{array}{l}\text { Dalam bab } 4 \text { tentang } \\
\text { Bulan Ramadhan yang }\end{array}$ \\
\hline
\end{tabular}




\begin{tabular}{|c|c|c|c|c|}
\hline & & $\begin{array}{l}\text { penilaian sesuai } \\
\text { tuntutan } \\
\text { penilaian } \\
\text { autentik }\end{array}$ & & $\begin{array}{l}\text { Indah ini penugasan, } \\
\text { pelatihan dan penilaian } \\
\text { sudah sesuai dengan } \\
\text { tuntutan } \\
\text { autentik. }\end{array}$ \\
\hline \multirow[t]{4}{*}{5} & \multirow[t]{4}{*}{$\begin{array}{l}\text { Keakuratan } \\
\text { Materi }\end{array}$} & $\begin{array}{l}\text { Pemilihan } \\
\text { wacana, teks, } \\
\text { gambar, dan } \\
\text { ilustrasi sesuai } \\
\text { dengan } \\
\text { kompetensi } \\
\text { yang harus } \\
\text { dicapai dan } \\
\text { bermanfaat bagi } \\
\text { pemenuhan } \\
\text { rasa ingin tahu } \\
\text { peserta didik }\end{array}$ & 7 & $\begin{array}{l}\text { Pemilihan wacana, teks, } \\
\text { gambar, dan ilustrasi } \\
\text { pada bab } 5 \text { tentang Rasul } \\
\text { Allah Idolaku sudah } \\
\text { sesuai } \\
\text { Kompetensi dengan } \\
\text { peserta didik, kasar } \\
\text { dalam materi sudah } \\
\text { memunculkan } \\
\text { pemahaman rasa ingin } \\
\text { tahu peserta didik serta } \\
\text { dapat dijadikan teladan } \\
\text { dalam kehidupan sehari } \\
\text { hari. Namun pada teks } \\
\text { masih banyak terdapat } \\
\text { kesalahan } \\
\text { penulisan materi. }\end{array}$ \\
\hline & & $\begin{array}{l}\text { Konsep r dan } \\
\text { teori } \quad \text { sesuai } \\
\text { dengan } \\
\text { sistematika } \\
\text { keilmuan }\end{array}$ & 7 & $\begin{array}{l}\text { Pada materi bab } 5 \\
\text { tentang Rasul Allah } \\
\text { Idolaku dari segi konsep } \\
\text { dan teori sudah sesuai } \\
\text { dengan KI/KD yang } \\
\text { harus dicapai peserta } \\
\text { didik. }\end{array}$ \\
\hline & & $\begin{array}{l}\text { Pemilihan } \\
\text { contoh sesuai } \\
\text { dengan } \\
\text { kompetensi } \\
\text { yang harus } \\
\text { dicapai }\end{array}$ & 7 & $\begin{array}{l}\text { Pemilihan contoh dalam } \\
\text { materi bab } 5 \text { tentang } \\
\text { Rasul Allah Idolaku } \\
\text { sudah sesuai dengan } \\
\text { Kompetensi Dasar yang } \\
\text { harus dicapai peserta } \\
\text { didik. }\end{array}$ \\
\hline & & $\begin{array}{l}\text { Pelatihan, } \\
\text { penugasan, dan } \\
\text { penilaian sesuai } \\
\text { tuntutan } \\
\text { penilaian } \\
\text { autentik }\end{array}$ & 8 & $\begin{array}{l}\text { Materi pada bab } 5 \\
\text { tentang Rasul Allah } \\
\text { Idolaku dalam pelatihan, } \\
\text { penugasan dan penilaian } \\
\text { sudah sesuai tuntutan } \\
\text { penilaian autentik. }\end{array}$ \\
\hline $\begin{array}{l}\text { Rangkuman } \\
\text { Kumulatif }\end{array}$ & \multicolumn{4}{|c|}{$\begin{array}{l}\text { Berdasarkan tabel diatas kelayakan isi keakuratan materi dari segi } \\
\text { penjelasan materi (wacana, teks, gambar ilustrasi, konsep, teori, } \\
\text { pemilihan contoh dan penugasan) sudah cukup baik pada bab } 1 \text {, bab } 3 \text {, } \\
\text { dan bab } 5 \text {, sedangkan pada bab } 2 \text { dan } 4 \text { sudah sesuai namun masih } \\
\text { terdapat kalimat yang tidak sesuai dengan kemampuan berpikir siswa, } \\
\text { serta minimnya contoh yang dapat memperdalam keilmuan peserta } \\
\text { didik. }\end{array}$} \\
\hline Jumlah Skor & \multicolumn{4}{|l|}{144} \\
\hline $\begin{array}{ll}\text { Jumlah } & \text { Skor } \\
\text { Maksimal } & \\
\end{array}$ & \multicolumn{4}{|l|}{200} \\
\hline $\begin{array}{l}\text { Presentase } \\
\text { Kelayakan }\end{array}$ & \multicolumn{4}{|c|}{$\begin{array}{l}\mathrm{P}=\frac{f}{N} \times 100 \% \\
\mathrm{P}=72 \%\end{array}$} \\
\hline
\end{tabular}


3. Kelayakan Isi Pendukung Pembelajaran sesuai dengan Permen 37 Tahun 2018

Tabel 3

Instrumen Penilaian Bahan Ajar Pendidikan Agama Islam

Kategori Penilaian :

\begin{tabular}{|l|l|l|l|l|l|l|l|l|l|}
\hline Kurang Sekali & \multicolumn{4}{l|}{ Kurang } & \multicolumn{2}{l|}{ Baik } & \multicolumn{2}{l|}{ Baik Sekali } \\
\hline 1 & 2 & 3 & 4 & 5 & 6 & 7 & 8 & 9 & 10 \\
\hline
\end{tabular}

\begin{tabular}{|c|c|c|c|c|}
\hline Pelajaran & Subkomponen & Butir & Ni lai & Alasan penilaian \\
\hline \multirow[t]{5}{*}{1} & \multirow[t]{5}{*}{$\begin{array}{l}\text { Pendukung } \\
\text { Materi } \\
\text { Pembelajaran }\end{array}$} & $\begin{array}{l}\text { Kesesuaian } \\
\text { dengan } \\
\text { perkembangan } \\
\text { ilmu }\end{array}$ & 7 & $\begin{array}{l}\text { Materi pada bab } 1 \text { tentang } \\
\text { Mari Membaca Surat At- } \\
\text { Tiin sudah sesuai dengan } \\
\text { perkembangan ilmu } \\
\text { pengetahuan } \\
\text { sekarang ini. }\end{array}$ \\
\hline & & $\begin{array}{l}\text { Kesesuaian } \\
\text { fitur/ contoh/ } \\
\text { latihan/ rujukan }\end{array}$ & 6 & $\begin{array}{l}\text { Dari segi kesesuaian fitur/ } \\
\text { contoh/ latihan/ rujukan, } \\
\text { pada bab } 1 \text { tentang Mari } \\
\text { Membaca Surat At-Tiin } \\
\text { sudah sesuai dan } \\
\text { mencerminkan kejadian } \\
\text { sehari-hari, namun masih } \\
\text { belum lengkap. }\end{array}$ \\
\hline & & $\begin{array}{l}\text { Pengembangan } \\
\text { wawasan } \\
\text { kebhinekaan }\end{array}$ & 5 & $\begin{array}{l}\text { Materi pada bab } 1 \text { tentang } \\
\text { Mari Membaca Surat At- } \\
\text { Tiin belum sesuai dengan } \\
\text { pengembangan wawasan } \\
\text { kebhinekaan. }\end{array}$ \\
\hline & & $\begin{array}{l}\text { Pengembangan } \\
\text { wawasan }\end{array}$ & 6 & $\begin{array}{l}\text { Pada materi tentang Mari } \\
\text { Membaca Surat At-Tiin } \\
\text { ini sudah sesuai dengan } \\
\text { pengembangan wawasan, } \\
\text { dapat dilihat dari } \\
\text { penjelasan makna surah } \\
\text { At-Tiin yang membuka } \\
\text { wawasan peserta didik } \\
\text { untuk lebih } \\
\text { memperbanyak ibadah } \\
\text { dan amal shaleh. }\end{array}$ \\
\hline & & $\begin{array}{l}\text { Tidak } \\
\text { mengandung } \\
\text { unsur SARA, } \\
\text { HAKI, } \\
\text { Pornografi, dan } \\
\text { Bias (gender, } \\
\text { wilayah, dsb) }\end{array}$ & 9 & $\begin{array}{l}\text { Materi pada bab } 1 \text { tentang } \\
\text { Mari Membaca Surat At- } \\
\text { Tiin sudah sesuai dan } \\
\text { tidak mengandung unsur } \\
\text { SARA, HAK, } \\
\text { Pornografi, dan Bias. }\end{array}$ \\
\hline 2 & $\begin{array}{l}\text { Pendukung } \\
\text { Materi } \\
\text { Pembelajaran }\end{array}$ & $\begin{array}{l}\text { Kesesuaian } \\
\text { dengan } \\
\text { perkembangan } \\
\text { ilmu }\end{array}$ & 7 & $\begin{array}{l}\text { Materi pada bab } 2 \text { tentang } \\
\text { Mengenal Nama Allah } \\
\text { dan Kitab-kitab-Nya } \\
\text { sudah sesuai dengan } \\
\text { perkembangan } \\
\text { pengetahuan ilmu } \\
\text { fenomena saat sekarang } \\
\text { ini. }\end{array}$ \\
\hline
\end{tabular}




\begin{tabular}{|c|c|c|c|c|}
\hline & & $\begin{array}{l}\text { Kesesuaian } \\
\text { fitur/ contoh/ } \\
\text { latihan/ rujukan }\end{array}$ & 6 & $\begin{array}{l}\text { Dari segi kesesuaian fitur/ } \\
\text { contoh/ latihan/ rujukan, } \\
\text { pada bab } 2 \text { tentang } \\
\text { Mengenal Nama Allah } \\
\text { dan Kitab-kitab-Nya } \\
\text { sudah sesuai, namun pada } \\
\text { sumber rujukan masih } \\
\text { kurang sesuai. }\end{array}$ \\
\hline & & $\begin{array}{l}\text { Pengembangan } \\
\text { wawasan } \\
\text { kebhinekaan }\end{array}$ & 7 & $\begin{array}{l}\text { Pada bab } 2 \text { materi tentang } \\
\text { Mengenal Nama Allah } \\
\text { dan Kitab-kitab-Nya } \\
\text { sudah terlihat } \\
\text { pengembangan wawasan } \\
\text { kebhinekaannya }\end{array}$ \\
\hline & & $\begin{array}{l}\text { Pengembangan } \\
\text { wawasan }\end{array}$ & 6 & $\begin{array}{l}\text { Pengembangan wawasan } \\
\text { pada materi tentang } \\
\text { Mengenal Nama Allah } \\
\text { dan Kitab-kitab-Nya, } \\
\text { sudah sesuai, namun pada } \\
\text { poin tertentu masih } \\
\text { kurang } \\
\text { penjelasannya. dalam }\end{array}$ \\
\hline & & $\begin{array}{l}\text { Tidak } \\
\text { mengandung } \\
\text { unsur SARA, } \\
\text { HAKI, } \\
\text { Pornografi, dan } \\
\text { Bias (gender, } \\
\text { wilayah, dsb) } \\
\end{array}$ & 9 & $\begin{array}{l}\text { Materi pada bab } 2 \text { tentang } \\
\text { Mengenal Nama Allah } \\
\text { dan Kitab-kitab-Nya tidak } \\
\text { mengandung unsur } \\
\text { SARA, HAKI, } \\
\text { Pornografi, dan Bias } \\
\text { (gender, wilayah, dsb) }\end{array}$ \\
\hline \multirow[t]{4}{*}{3} & \multirow[t]{4}{*}{\begin{tabular}{|l|} 
Pendukung \\
Materi \\
Pembelajaran
\end{tabular}} & $\begin{array}{l}\text { Kesesuaian } \\
\text { dengan } \\
\text { perkembangan } \\
\text { ilmu }\end{array}$ & 8 & \begin{tabular}{lcr}
\multicolumn{3}{l}{ Materi bab 3 tentang Cita- } \\
citaku Menjadi Anak \\
Sholeh sudah sesuai \\
dengan & fenomena \\
kehidupan sehari-hari.
\end{tabular} \\
\hline & & $\begin{array}{l}\text { Kesesuaian } \\
\text { fitur/ contoh/ } \\
\text { latihan/ rujukan }\end{array}$ & 8 & $\begin{array}{l}\text { Kesesuaian fitur/ contoh/ } \\
\text { latihan/ rujukan pada bab } \\
3 \text { tentang Cita-citaku } \\
\text { Menjadi Anak Sholeh } \\
\text { sudah sesuai dengan } \\
\text { didukung adanya gambar } \\
\text { ilustrasi yang mendukung }\end{array}$ \\
\hline & & $\begin{array}{l}\text { Pengembangan } \\
\text { wawasan } \\
\text { kebhinekaan }\end{array}$ & 8 & $\begin{array}{l}\text { Wawasan kebhinekaan } \\
\text { pada bab } 3 \text { materi tentang } \\
\text { Cita-citaku Menjadi Anak } \\
\text { Sholeh sudah sesuai dan } \\
\text { sudah terlihat pada poin } \\
\text { "Indahnya Saling } \\
\begin{array}{l}\text { Menghargai } \\
\text { Teman" Sesama }\end{array}\end{array}$ \\
\hline & & $\begin{array}{l}\text { Pengembangan } \\
\text { wawasan }\end{array}$ & 7 & $\begin{array}{l}\text { Pengembangan wawasan } \\
\text { pada bab } 3 \text { ini sudah } \\
\text { tampak, namun masih } \\
\text { terdapat kalimat yang } \\
\text { membingungkan peserta } \\
\text { didik. }\end{array}$ \\
\hline
\end{tabular}




\begin{tabular}{|c|c|c|c|c|}
\hline & & $\begin{array}{l}\text { Tidak } \\
\text { mengandung } \\
\text { unsur SARA, } \\
\text { HAKI, } \\
\text { Pornografi, dan } \\
\text { Bias (gender, } \\
\text { wilayah, dsb) }\end{array}$ & 9 & $\begin{array}{l}\text { Materi tentang Cita-citaku } \\
\text { Menjadi Anak Sholeh } \\
\text { tidak mengandng unsur } \\
\text { SARA, HAKI, } \\
\text { Pornografi, dan Bias. }\end{array}$ \\
\hline \multirow[t]{5}{*}{4} & \multirow[t]{5}{*}{$\begin{array}{l}\text { Pendukung } \\
\text { Materi } \\
\text { Pembelajaran }\end{array}$} & $\begin{array}{l}\text { Kesesuaian } \\
\text { dengan } \\
\text { perkembangan } \\
\text { ilmu }\end{array}$ & 7 & $\begin{array}{l}\text { Materi pada bab } 4 \text { tentang } \\
\text { Bulan Ramadhan yang } \\
\text { Indah sudah sesuai } \\
\text { dengan perkembangan } \\
\text { ilmu, terutama dalam } \\
\text { kehidupan sehari-hari. }\end{array}$ \\
\hline & & $\begin{array}{l}\text { Kesesuaian } \\
\text { fitur/ contoh/ } \\
\text { latihan/ rujukan }\end{array}$ & 7 & $\begin{array}{l}\text { Dari segi kesesuaian fitur/ } \\
\text { contoh/ latihan/ rujukan } \\
\text { sudah sesuai, namun } \\
\text { masih terdapat kekeliruan } \\
\text { dibagian soal-soal latihan }\end{array}$ \\
\hline & & $\begin{array}{l}\text { Pengembangan } \\
\text { wawasan } \\
\text { kebhinekaan }\end{array}$ & 5 & $\begin{array}{l}\text { Penjelasan materi bab } 4 \\
\text { tentang Bulan Ramadhan } \\
\text { yang Indah belum terlihat } \\
\text { penjelasan pengembangan } \\
\text { wawasan kebhinekaan. }\end{array}$ \\
\hline & & $\begin{array}{l}\text { Pengembangan } \\
\text { wawasan }\end{array}$ & 8 & $\begin{array}{l}\text { Dari segi pengembangan } \\
\text { wawasan, materi pada bab } \\
4 \quad \text { tentang } \\
\text { Ramadhan yang } \\
\text { sudah Indah } \\
\text { sudah sesuai. }\end{array}$ \\
\hline & & $\begin{array}{l}\text { Tidak } \\
\text { mengandung } \\
\text { unsur SARA, } \\
\text { HAKI, } \\
\text { Pornografi, dan } \\
\text { Bias (gender, } \\
\text { wilayah, dsb) }\end{array}$ & 9 & $\begin{array}{l}\text { Materi tentang Bulan } \\
\text { Ramadhan yang Indah } \\
\text { tidak mengandung unsur } \\
\text { SARA, HAKI, } \\
\text { Pornografi, dan Bias. }\end{array}$ \\
\hline \multirow[t]{4}{*}{5} & \multirow[t]{4}{*}{$\begin{array}{l}\text { Pendukung } \\
\text { Materi } \\
\text { Pembelajaran }\end{array}$} & $\begin{array}{l}\text { Kesesuaian } \\
\text { dengan } \\
\text { perkembangan } \\
\text { ilmu }\end{array}$ & 7 & $\begin{array}{lr}\text { Materi bab } 5 & \text { tentang } \\
\text { Rasul Allah Idolaku sudah } \\
\text { sesuai } & \text { dengan } \\
\text { perkembangan } & \text { ilmu } \\
\text { dalam kedidupan } & \text { sehari- } \\
\text { hari. } & \\
\end{array}$ \\
\hline & & $\begin{array}{l}\text { Kesesuaian } \\
\text { fitur/ contoh/ } \\
\text { latihan/ rujukan }\end{array}$ & 8 & $\begin{array}{l}\text { Kesesuaian fitur/ contoh/ } \\
\text { latihan/ rujukan pada bab } \\
5 \text { tentang Rasul Allah } \\
\text { Idolaku sudah sesuai. }\end{array}$ \\
\hline & & $\begin{array}{l}\text { Pengembangan } \\
\text { wawasan } \\
\text { kebhinekaan }\end{array}$ & 8 & $\begin{array}{lr}\text { Materi tentang } & \text { Rasul } \\
\text { Allah Idolaku pada bab 5 } \\
\text { ini sudah } r \text { terlihat } \\
\text { pengembangan } & \text { wawasan } \\
\text { kebhinekaan } & \text { melalui } \\
\text { kisah-kisah } & \text { Rasul-rasul } \\
\text { Allah. }\end{array}$ \\
\hline & & $\begin{array}{l}\text { Pengembangan } \\
\text { wawasan }\end{array}$ & 7 & $\begin{array}{l}\text { Dari segi pengembangan } \\
\text { wawasan, pada bab } 5 \\
\text { tentang Rasul Allah } \\
\text { Idolaku juga sudah mulai }\end{array}$ \\
\hline
\end{tabular}




\begin{tabular}{|c|c|c|c|c|}
\hline & & & & $\begin{array}{l}\text { tampak dari kisah-kisah } \\
\text { perjuangan dakwah Rasul- } \\
\text { rasul Allah. }\end{array}$ \\
\hline & & $\begin{array}{l}\text { Tidak } \\
\text { mengandung } \\
\text { unsur SARA, } \\
\text { HAKI, } \\
\text { Pornografi, dan } \\
\text { Bias (gender, } \\
\text { wilayah, dsb) }\end{array}$ & 9 & $\begin{array}{l}\text { Pada bab } 5 \text { tentang Rasul } \\
\text { Allah Idolaku ini tidak } \\
\text { terdapat unsur SARA, } \\
\text { HAKI, Pornografi, dan } \\
\text { Bias. }\end{array}$ \\
\hline $\begin{array}{l}\text { Rangkuman } \\
\text { Kumulatif }\end{array}$ & \multicolumn{4}{|c|}{$\begin{array}{l}\text { Berdasarkan data diatas, dilihat dari segi pendukung pembelajaran } \\
\text { (kesesuaian pengembangan ilmu, pengembangan wawasan, pengembangan } \\
\text { wawasan kebhinekaan, dan tidak mengandung unsur SARA, HAKI, } \\
\text { Pornografi, dan Bias) pada Bab } 2,3 \text { dan } 5 \text { sudah sesuai, secara keseluruhan } \\
\text { bab tidak mengandung SARA, HAKI, Pornografi, dan Bias. Sedangkan } \\
\text { pada Bab } 1 \text { dan } 4 \text { pada poin pengembangan wawasan kebhinekaan masih } \\
\text { belum terdapat contoh yang sesuai dengan materi pembelajaran. }\end{array}$} \\
\hline Jumlah Skor & \multicolumn{4}{|l|}{183} \\
\hline $\begin{array}{l}\text { Jumlah Skor } \\
\text { Maksimal }\end{array}$ & \multicolumn{4}{|l|}{250} \\
\hline $\begin{array}{l}\text { Presentase } \\
\text { Kelayakan }\end{array}$ & \multicolumn{4}{|l|}{$\begin{array}{l}\mathrm{P}=\frac{f}{N} \times 100 \% \\
\mathrm{P}=73,2 \%\end{array}$} \\
\hline
\end{tabular}

Berdasarkan paparan data diatas hasil kelayakan isi LKS Pintar Pendidikan Agama Islam Berkarakter secara keseluruhan dengan menggunakan rumus persentase yaitu :

$$
\begin{gathered}
P=\frac{f}{N} \times 100 \% \\
\text { Persentase kelayakan }=\left(\frac{\text { Skor Jawaban }}{\text { Skor Maksimal }}\right) \times 100 \%
\end{gathered}
$$

Keterangan :

$\mathrm{P}=$ Persentase skor

$\mathrm{f}=$ Jumlah skor yang diperoleh

$\mathrm{N}=$ Jumlah skor maksimal

Tabel 4

Hasil Kelayakan Isi

\begin{tabular}{|l|l|}
\hline Subkomponen & Skor Kelayakan \\
\hline Kesesuaian materi KI/KD & $65 \%$ \\
\hline Keakuratan Materi & $72 \%$ \\
\hline Pendukung Materi Pembelajaran & $73,2 \%$ \\
\hline Total & $\mathbf{2 1 0 , 2}$ \\
\hline Rata-rata & $\mathbf{7 0} \%$ \\
\hline
\end{tabular}

Berdasarkan tabel diatas, dapat dilihat persentase kelayakan isi LKS Pintar Pendidikan Agama Islam Berkarakter secara keseluruhan subkomponen memperoleh rata-rata $70 \%$ dan termasuk dalam kategori "layak digunakan" untuk buku pendamping pembelajaran PAI. Sedangkan 30\% lainnya tidak layak. Hasil yang diperoleh ini sudah berdasarkan kategori kelayakan bahan ajar, dimana 60\%-79,9\% termasuk dalam kategori layak, sedangkan $\leq 49,9 \%$ termasuk dalam kategori tidak layak.

\section{B. Kelayakan Isi LKS Pintar Pendidikan Agama Islam Berkarakter Kelas V SD}

\section{Pelajaran $1:$ Mari Membaca Surat At-Tiin}

Berdasarkan analisis yang telah dilakukan, pada bab 1 materi tentang Mari Membaca Surat At-Tiin belum sesuai dengan KI-KD. Dalam materi pelajaran 1 tersebut telah menjelaskan pengertian surat At-Tiin, bagaimana hukum bacaan tajwid surat At-Tiin, menghafalkan surat At-Tiin melalui penggalan-penggalan perayat disertai terjemahannya, serta sudah menjelaskan apasaja makna dan isi kandungan dari surat At-Tiin. Namun surat 
Al-Ma'un belum dijelaskan dalam materi bab 1 ini. Pemilihan wacana, teks, gambar ilustrasi sudah sesuai dengan kemampuan berpikir siswa SD.

Pada bab 1 ini terdapat gambar ilustrasi yang sesuai dengan imdikator pembelajaran yakni menampilkan gambar buah tin dan zaitun sebagai contoh nyata bahwa penjelasan dalam surat At-Tiin memang benar adanya dalam kehidupan sehari-hari. Penjelasan makna dan isi kandungan surah sesuai kemampuan berpikir siswa. Namun, pada bab 1 belum tampak contoh sikap yang mencerminkan pengamalan dari surat At-Tiin. Pada materi Mari Membaca Surat At-Tiin secara keseluruhan tidak terdapat unsur SARA, HAKI, pornografi dan Bias (gender, wilayah, dan sebagainya).

\section{Pelajaran 2 : Mengenal Nama Allah dan Kitab-kitabnya}

Berdasarkan analisis yang telah dilakukan, pada bab 2 materi tentang Mengenal Nama Allah dan Kitab-kitab-Nya secara keseluruhan sudah sesuai dengan KI-KD. Selain itu, pada bab 2 materi tentang Mengenal Nama Allah dan Kitab-kitab-Nya, sudah menggunakan contoh ilustrasi yang sesuai. Pada halaman 15 dan 16 terdapat gambar kitab Zabur, kitab Taurat, kitab Injil dan Al-Qur'an serta penjelasannya mengenai Rasul yang diutus untuk menerima dan menyiarkan ajaran masing-masing kitab tersebut.

Selanjutnya, pada kesesuaian rujukan, penjelasan materi pada bab 2 ini diambil dari sebuah blog dari internet yang tidak mencantumkan sumber yang jelas. Pada poin latihan, penugasan, dan penilaian sudah sesuai dengan kemampuan berpikir siswa. Pada kolom refleksi juga sudah menampilkan contoh kisah teladan yang sesuai, serta dapat menambah pengetahuan dan wawasan peserta didik. Pada materi Mengenal Nama Allah dan Kitabkitabnya secara keseluruhan tidak terdapat unsur SARA, HAKI, Pornografi dan Bias (gender, wilayah, dan sebagainya)

\section{Pelajaran 3 : Cita-citaku Menjadi Anak Sholeh}

Secara keseluruhan, pada bab 3 materi tentang Cita-citaku Menjadi Anak Sholeh sudah sesuai dengan KI-KD, dari segi keakuratan materi dan pendukung pembelajaran juga sudah sesuai. Namun, ada beberapa poin yang masih perlu diperhatikan. Pada bab 3 halaman 24 terdapat istilah yang sulit bagi siswa. Penggunaan kata takzim dan khidmat disini tidak diberikan penjelasan yang rinci mengenai defenisi kata tersebut.

Kemudian dari segi pendukung materi, pada bab 3 tentang Cita-citaku Menjadi Anak Sholeh sudah sesuai. Disini terdapat banyak gambar ilustrasi yang membuat penjelasan materi tampak lebih menarik. Pada pengembangan wawasan kebhinekaan juga sudah tampak pada bab 3 ini pada poin "Indahnya Saling Menghargai Sesama Teman", melalui contoh-contoh perbuatan saling menghargai sesama dimasyarakat, serta bentuk toleransi dalam kehidupan sehati-hari. Selanjutnya pada kolom refleksi juga menampilkan kisah hikmah untuk menambah wawasan peserta didik. Dalam penugasan, latihan dan penilaian tingkat kesulitan soal juga sudah sesuai dengan kemampuan berpikir peserta didik. Pada bab 3 ini juga tidak terdapat unsur SARA, HAKI, Pornografi dan Bias (gender, wilayah, dsb).

\section{Pelajaran 4 : Bulan Ramadhan yang Indah}

Berdasarkan hasil analisis yang telah dilakukan pada bab 4 materi tentang Bulan Ramadhan yang Indah secara keseluruhan dari segi kesesuaian uraian materi KI-KD, keakuratan materi dan pendukung pembelajaran sudah sesuai. Namun masih ada beberapa poin penting yang perlu diperhatikan. Materi yang dijelaskan sudah sesuai dengan tuntutan kompetensi dasar yang harus dipenuhi pesera didik. Penjelasan materi pada bab 4 ini juga sudah rinci, hanya saja masih terdapat banyak kesalahan dalam penulisan. Hal ini dapat dilihat pada halaman 30 dan 32. Selain itu, pada halaman 31, penggunaan kata Taklifan tidak diberikan penjelasan yang rinci mengenai defenisi kata tersebut, sehingga dapat membingungkan peserta didik. Pada bab 4, tidak ditemukan gambar ilustrasi yang dapat membantu pemahaman peserta didik melalui penjelasan materi. 
Selain itu, pada soal latihan dan penugasan terdapat pertanyaan yang membingungkan yaitu "dalam satu tahun, kita diharamkan berpuasa sebanyak ..." jawabannya ada 3, yaitu: pada Hari Raya Idul Fitri, Hari Raya Idul Adha, dan Hari Tasyrik $(11,12,13)$. Sedangkan yang dijelaskan dalam materi bab 4 ini hanya 2 saja, yaitu pada Hari Raya Idul Fitri, dan Hari Raya Idul Adha. Kemudian, pada materi bab 4 tentang Bulan Ramadhan yang Indah tidak terdapat unsur SARA, HAKI, Pornografi, dan Bias (gender, wilayah, dan sebagainya)

\section{Pelajaran 5 : Rasul Allah Idolaku}

Berdasarkan hasil analisis yang telah dilakukan, materi pada bab 5 tentang Rasul Allah Idolaku dari segi kesesuaian dengan KI-KD masih belum lengkap dan tidak sesuai dengan KI-KD. Disini dapat dilihat materi yang seharusnya dijelaskan pada bab 5 ini mencakup keteladanan Nabi Daus a.s, Sulaiman a.s, Ilyas a.s, Ilyasa' a.s, dan Muhammad Saw. Namun, dalam bab 5 ini tidak ada dijelaskan keteladanan Nabi Muhammad Saw. Namun dari segi keakuratan dan pendukung materi pembelajaran, materi tentang Rasul Allah Idolaku ini sudah lengkap.

Dilihat dari pemilihan wacana dan teks sudah sesuai dengan tingkat kemampuan berpikir peserta didik. didalam materi juga sudah memunculkan pemahaman rasa ingin tahu peserta didik hanya saja masih terdapat kesalahan dalam penulisan kata. Pada halaman 37-38 penulisan nama Nabi menggunakan bahasa Arab yang salah (terbalik). Konsep dan teori pada materi Rasul Allah Idolaku sudah sesuai dengan sistematika keilmuan. Selain itu, kesesuaian fitur, dan contoh serta kisah hikmah pada materi Rasul Allah Idolaku ini dapat menambah wawasan pengetahuan peserta didik. Terakhir, pada materi Rasul Allah Idolaku sudah tampak perbuatan kebhinekaan, bagaimana Rasul-rasul Allah tolong menolong tanpa pamrih kepada siapapun, bahkan kepada orang yang bukan bersal dari agama islam, serta dakwah dan perjuangan beliau dalam menyiarkan agama islam pada masa itu. Kemudian, dalam penjelasan materi bab 5 tentang Rasul Allah Idolaku tidak mengandung unsur SARA, HAKI, Pornografi, dan Bias (gender, wilayah, dan lainnya).

Buku LKS Pintar Pendidikan Agama Islam Berkarakter dari keseluruhan sudah layak digunakan sebagai buku acuan pendamping dalam pembelajaran PAI di sekolah dasar. Pada penulisan kalimat masih banyak ditemui kesalahan-kesalahan serta penggunaan kalimat yang cukup sulit bagi peserta didik kelas V SD. Selain itu penggunaan buku LKS ini cukup praktis digunakan saat kondisi pembelajaran secara daring. Namun, dalam pemahaman istilah perlu didampingi guru atau orang tua agar siswa lebih paham mengenai maksud dari beberapa istilah yang sulit tersebut.

\section{Kesimpulan}

Berdasarkan kelayakan isi secara keseluruhan subkomponen, LKS ini termasuk dalam kategori layak digunakan sebagai buku acuan pendamping pembelajaran di sekolah. LKS Pintar Pendidikan Agama Islam Berkarakter memperoleh persentase sebesar 70\% layak dan 30\% kurang layak. Artinya LKS Pintar Pendidikan Agama Islam Berkarakter Kelas V SD sudah layak untuk diajarkan karena memperoleh persentase $70 \%$, dimana angka tersebut menunjukkan layak digunakan sebagai buku pendamping pembelajaran di sekolah

\section{Daftar Kepustakaan}

Aini, R. \& N. H. (2020). Analisis Kualitas Buku Ajar Pendidikan Agama Islam Di Era Revolusi 4.0. As-Salam, Vol 4, No, 350.

Aryani, F. (2011). Jurnal Pendidikan Mtematika: Pengambangan LKS untuk Metode Penemuan Terbimbing pada Pembelajaran Matematika kelas VIII di SMP Negeri 18 Palembang. Unsri, Vol 5, No, 131.

Ghony dan Fauzan Almansur, D. (2012). Metodologi Penelitian Kualitatif. Ar-Ruzz Media. 
Husnawati. (2018). Analisis Kelayakan Isi Buku Ajar Pendidikan Agama Islam dan Budi Pekerti Kelas II SDN 8 Menteng Palangka Raya Penerbit Kementerian Pendidikan Dan Kebudayaan. 113.

Kholida, N. M. \&

R. S. (2021). Peran Kegiatan Pengajian Sebagai Wadah Pelaksanaan Pendidikan Islam Berbasis Masyarakat. Jurnal Pendidikan Tambusai, 5, 2.

Masduqi, M. T. (2014). Analisis Buku Pelajaran Pendidikan Agama Islam Sekolah Menengah Atas Kelas X Kurikulum 2013 Berdasarkan Pendekatan Saintifik. Universitas Islam Negeri Sunan Kalijaga Yogyakarta.

Nasucha, J. A. (2019). Nilai Karakter pada Mata Pelajaran PAI dalam Kurikulum 2013 (Analisis Buku Siswa tingkat 1 Sekolah Dasar). E-Journal Ikhac, Vol 2, No, 115.

Nurochim, S. N. (2021). Analisis Isi Sikap Sosial dalam Buku Ajar Pendidikan Agama Islam dan Budi Pekerti. Al-Hikmah, Vol 3, No, 42.

Ramah, S. \& M. R. (2018). Analisis Buku Ajar Bahasa Arab Madrasah Aliyah Kurikulum 2013. E-Journal STAIN Curup, Vol 2, No, 145.

Samrin. (2015). Pendidikan Agama Islam dalam Sistem Pendidikan Nasional Indonesia. AlTa'dib, 8, 107.

Widyantini, T. (2013). Penyusunan Lembar Kegiatan Siswa (LKS) sebagai Bahan Ajar. PPPPTK Matematika.

http://p4tkmatematika.kemdikbud.go.id/artikel/2013/10/07/penyusunanlembarkerj asiswa/ 